\title{
Investigation of current threats to the existence of Brackenridgea zanguebarica in a small geographic area in Vhembe, Limpopo Province, South Africa
}

\author{
MAKUÉTÉ ANDRÉ PATRICK TIAWOUN ${ }^{1, \bullet}$, MILINGONI PETER TSHISIKHAWE ${ }^{1}$, \\ EASTONCE TENDAYI GWATA ${ }^{2}$ \\ ${ }^{1}$ Department of Botany, School of Mathematical and Natural Sciences, University of Venda. Private Bag X5050, Thohoyandou, Limpopo, 0950, South \\ Africa. Tel.: +27-78-185 4339, `email: maptiaw@yahoo.fr \\ ${ }^{2}$ Department of Plant Production, School of Agriculture, University of Venda. Private Bag X5050, Thohoyandou 0950, South Africa
}

Manuscript received: 12 April 2019. Revision accepted: 1 April 2019.

\begin{abstract}
Tiawoun MAP, Tshisikhawe MP, Gwata ET. 2019. Geometric morphometry of pupae to identify four medically important flies (Order: Diptera) in Thailand. Biodiversitas 20: 1504-1509. Brackenridgea zanguebarica is one of the most threatened plant species in South Africa, found only in Thengwe village, Vhembe District Municipality, Limpopo Province, South Africa. Due to the high traditional use of its stem bark and root, the species is now facing the threat of extinction. It has been assessed in accordance with the IUCN Red List of South Africa as a critically endangered species. The aim of this study was to investigate the impact of current threats to the population in the Brackenridgea Nature Reserve, in order to improve its conservation measures. The study was carried out in the reserve, where 10 belt transects of $50 \mathrm{~m}$ long and $20 \mathrm{~m}$ wide were laid at regular intervals of $5 \mathrm{~m}$ to investigate the population of $B$. zanguebarica. Individuals were counted and the structural parameters, e.g. tree height and stem diameter size of each were measured, while the impact of plant harvesting was estimated using a sliding scale of 0 to 5 . The structure of the populations in terms of the stem diameter size classes was dominated by juvenile plants that showed the bell shape pattern. In addition, $59.9 \%$ out of the total plants recorded presented signs of plant parts extraction, with the stem bark the main part extracted. The population status of $B$. zanguebarica was unstable and under severe threat due to the destructive harvesting of the mature tree parts, leading to poor regeneration of individuals. It is thus recommended that in order to improve its conservation measures.
\end{abstract}

Keywords: Brackenridgea zanguebarica, conservation, endemic plant, harvesting, population status

\section{INTRODUCTION}

The extinction and declining populations of many rare plant species worldwide are increasing at an alarming rate. This escalating biodiversity crisis is an indication that the current diversity of nature is not capable of supporting the pressure that the growing humanity is placing on the planet. Overexploitation of the plants' roots and bark has endangered the survival of the mature trees as these are unable to fully recover, hence, eventually hindering fruit production but rather causing poor or slow seedling recruitment (Dhillion and Gustad 2004). The continued decline, coupled with the plant's endemism status and the small geographic range where this tree species occurs, make it particularly vulnerable to natural catastrophes. Rare species restricted to one or to a few populations have a greater chance of becoming extinct (Van Dyke 2003). In this scenario, B. zanguebarica has been classified as a protected tree in the Red List of South Africa. In terms of the IUCN criteria, this plant has been listed under the category of critically endangered plant in South Africa (Williams and Raimondo 2008).

Brackenridgea zanguebarica, a small deciduous tree, belongs to the family, Ochnaceae. It has a restricted geographic distribution and its natural distribution zone is known from only one population confined to a small area within Thengwe, in the Vhembe District of Limpopo Province, therefore, endemic to the Vhembe District. The species is habitat-specific as many other rare and endemic plant species have only one or few ranges of distribution. It grows naturally in stony, light gray and shallow sandy loam soil, at low altitude, in open areas with low grass cover (Mutshinyalo 2011). In South Africa, B. zanguebarica is considered a critically endangered plant species according to the South African National Biodiversity Institute (SANBI) Red List categories (Raimondo et al. 2009), mainly due to severe harvesting from traditional herbalists, and commercial harvesting of its bark and roots to meet growing market demand. It is an important indigenous medicinal plant used by the Venda people, mostly for magical purposes (Tshisikhawe and Van Rooyen 2012).

Due to the high anthropogenic pressure, harvesting has depleted the population outside the Brackenridgea Nature Reserve as well as within the reserve, although to a lesser extent (Williams and Raimondo 2008); not a single plant seems to be available outside the reserve. Nowadays, this species only has a small population and is very threatened across its extremely narrow range of distribution. The number of individuals have fluctuated over time, however, the remaining population within the reserve it is not a guarantee for the survival of this species due to the destructive harvesting that is taking place within the reserve. 
This species has been listed as protected since the establishment, in 1987, of the Brackenridgea Nature Reserve by the Provincial Limpopo Department of Economic Development, Environment and Tourism (LEDET). Despite its protection, this tree species still faces a high risk of extinction over its small geographical range due to unsustainable harvesting of its stem bark and root. The population density of $B$. zanguebarica inside and outside the reserve was investigated in 1990 and 1997. In this regard, Todd et al. (2004) reported that uncontrolled harvesting has resulted in an $86 \%$ decline in density from 140 trees/ha in 1990, to 25 trees/ha in 1997. The reserve, obviously, is not performing its role of in situ conservation of biological diversity confirming the prediction which states that, if the intensity of collecting this plant continues at this rate, this species will become extinct in South Africa (Mutshinyalo 2011). Action, therefore, must be taken for the sustainable conservation of this plant species by setting up an effective management scheme.

The conservation of this endemic tree species is hampered by the dearth of information on its population biology and ecology. Because of this, the present study was undertaken to understand how the current threats affect the population biology and ecology of this endemic tree species in the reserve. The specific objectives of the study were, to (i) Assess the population density and structure of B. zanguebarica; (ii) examine the harvesting impact on the population structure and the natural regeneration of $B$. zanguebarica. The findings of this study might contribute to useful information for the planning of efficient conservation strategies for this critically endangered plant species in the Brackenridgea Nature Reserve by LEDET.

\section{MATERIALS AND METHODS}

\section{Study site}

The study was conducted in The Brackenridgea Nature Reserve (BNR) also known as the Mutavhatsindi Nature Reserve (MNR). The reserve is currently 110 ha in size and the conservation state of this species in this site is not satisfactory due to limited reserve size (Tshisikhawe et al. 2013). The soil is mainly stony and thin with sandy loam (Mutshinyalo 2011). The reserve is within the savanna biome and the vegetation in and around the reserve is classified as Vhavenda Miombo (Mucina and Rutherford 2006), and it is situated in the Vhembe District Municipality of the Limpopo Province (Figure 1).

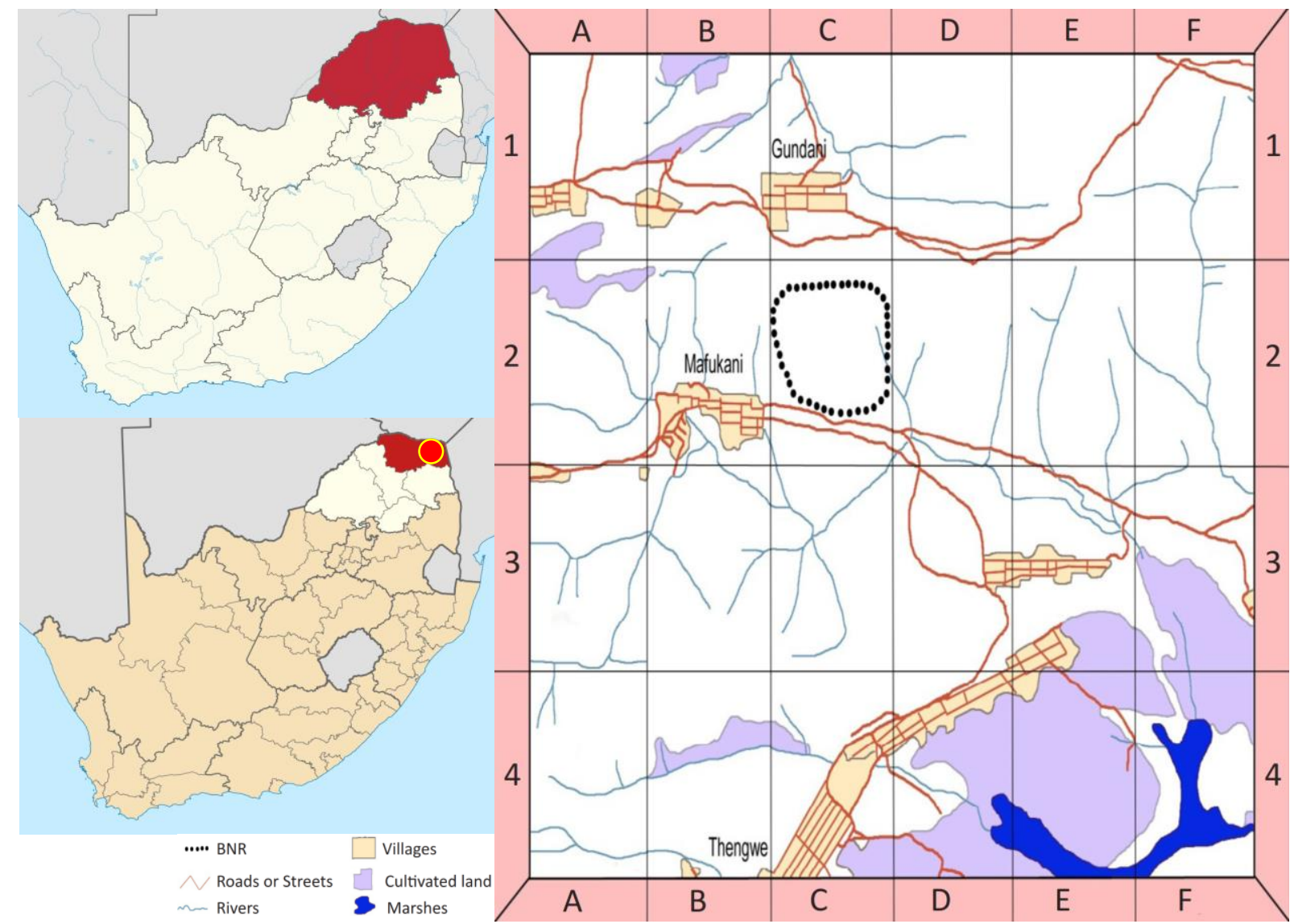

Figure 1. Map of the Thengwe village showing the Brackenridgea Nature Reserve (BNR), in Vhembe District Municipality, Limpopo Province, South Africa (Tshisikhawe et al. 2013; Wikipedia) 
Its coordinates are $22^{\circ} 24^{\prime} 0.0^{\prime \prime}-23^{\circ} 36^{\prime} 0.0^{\prime \prime} \mathrm{S}$ and $29^{\circ}$ $12^{\prime} 0.0^{\prime}$ ' and $31^{\circ} 12^{\prime} 0.0^{\prime}$ E. The reserve is at an average elevation of 600 meters above sea level. The mean annual rainfall is about $350 \mathrm{~mm}$, but it occasionally varies with the annual mean maximum and minimum temperature being $26.5^{\circ} \mathrm{C}$ and $16^{\circ} \mathrm{C}$, respectively (Mzezewa et al. 2010). The temperature, however, does not vary much over the seasons. Rainfall occurs mainly during summers, from October to March, and mild winters occur from April to September (Mucina and Rutherford 2006). The vegetation of the region is dominated mostly by Colophospermum mopane, Terminalia sericea, Grewia flava and Combretum apiculatum (Venter and Witkowski 2010). The dominant ethnic population group in the surrounding area of the BNR is the Vhavenda who survive mainly on farming.

\section{Field data collection}

A field survey was undertaken and samplings collected within the BNR in Thengwe village from November to December 2016. The population sampling was conducted through the vertical belt transect method of Michael (1990). This method is appropriate for recording the presence of as many taxa as possible, in the study area to produce detailed information on the population status of this plant species. In order to examine the population status of $B$. zanguebarica, it is necessary to record the presence of as many trees as possible that will be representative of the population. Ten belt transects of $50 \mathrm{~m}$ long and $20 \mathrm{~m}$ wide were laid at regular intervals of $5 \mathrm{~m}$ in the study area. Each belt transect was divided into two sub-belts of $50 \mathrm{~m} \times 10 \mathrm{~m}$ for ease of sampling and five quadrats of $10 \times 10 \mathrm{~m}$ were laid in each sub-belt as replicates. Ten quadrats were derived from each belt transect. One hundred quadrats of size $10 \times 10 \mathrm{~m}$, therefore, were sampled in the study site covering an area of 1 ha. The coordinates of all quadrats were recorded using a Global Positioning System (GPS).

All the B. zanguebarica trees, from seedlings to adult plants that were encountered within each quadrat were counted and different parameters, such as the height and stem diameter were measured. In addition, the evidence of anthropogenic bark and root harvested were estimated and scored.

\section{Population density and structure}

In each quadrat, the diameter of all samples of $B$. zanguebarica was measured and, the number of individuals in different diameter size classes was enumerated to assess the population structure. The diameter of seedlings and saplings were measured using tree caliper at the base of the plant, while larger individuals with $\mathrm{DBH} \geq 5 \mathrm{~cm}$ were obtained by measuring their circumference at $1.3 \mathrm{~m}$ from the ground level with a tape measure. In order to study the stem size class distribution, seedlings were regarded as samples with a stem diameter $\leq 0.5 \mathrm{~cm}$ and height $<50 \mathrm{~cm}$, whereas saplings were samples with a stem diameter between 0.5 and $1.99 \mathrm{~cm}$ and with height $>50 \mathrm{~cm}$. The $\mathrm{DBH}$ of larger individuals were recorded and grouped into eight DBH classes assigned at $4 \mathrm{~cm}$ DBH increments: 2.0 $5.9 \mathrm{~cm}, 6.0-9.9 \mathrm{~cm}, 10.0-13.9 \mathrm{~cm}, 14.0-17.9 \mathrm{~cm}, 18.0-21.9$ $\mathrm{cm}, 22.0-25.9 \mathrm{~cm}, 26.0-29.9 \mathrm{~cm}$ and $30.0-33.9 \mathrm{~cm}$ (Vesa et al. 2015). These DBH classes were then, separated into three arbitrary categories based on the age stage for easy analysis: juveniles were those with $2.0 \mathrm{~cm} \leq \mathrm{DBH}<5.9 \mathrm{~cm}$ and $6.0 \mathrm{~cm} \leq \mathrm{DBH}<9.9 \mathrm{~cm}$; sub-adults: $10.0 \mathrm{~cm} \leq \mathrm{DBH}$ $<13.9 \mathrm{~cm}$ and $14.0 \mathrm{~cm} \leq \mathrm{DBH}<17.9 \mathrm{~cm}$ and adults: $\mathrm{DBH}$ $\geq 18.0 \mathrm{~cm}$.

\section{Plant parts harvested}

Because of only some plant parts of this species were being over-collected, two major anthropogenic harvesting practices (root and bark) were investigated. The occurrence of any evidence of bark removal and root excavated was recorded for each sample; also chopped stems were noted as well. In order to investigate the impact of harvesting practices on the population structure of this species, all samples were divided into different size classes based on the stem diameter and harvesting practices were measured by classifying the proportion of extracted bark or root.

The intensity of bark harvesting was estimated and recorded in a sliding scale following the visual classification described (Cunningham 1993). Cunningham (1993), used the visual method to classify the levels of damage intensity into seven categories based on the proportion of bark collected from each sample. This method was applied in this study and interpreted by using the terms of Tshisikhawe et al. (2012) with slight modification as follows: 0: No damaged (Null); I: Individual with $\leq 10 \%$ damaged (Trace); II: Individual with 11-25\% damaged (Light); III: individual with 26-50\% damaged (Moderate); IV: Individual with 51-75\% damaged (Severe); V: Individual with 76-100\% damaged (Very severe) (Table 1 and 2).

Root excavated was assessed according to the level of disturbed surface area at the base of the stem as applied in the study of Catha edulis (Botha 2004). Roots excavated were recorded and scored in five classes as follows ${ }^{15}$ : 0 : no harvesting; I: <10 \%; II: 11-25 \%; III: 26-50 \%; IV: 51-75 $\%$; V>76\%, and then, interpreted by using the above terms of Tshisikhawe et al. (2012).

\section{Natural regeneration}

In each quadrat, the number of seedlings and saplings were counted and at the same time, all cut stumps with sprouting ability were recorded.

\section{Data analysis}

The numbers of the individual samples in different diameter size classes and distribution were used to create Bar graphs of the population structure. Data were entered into Microsoft Excel Spreadsheet 2010 and analyzed using SPSS version 24. Kruskal-Wallis Test (Nonparametric ANOVA) was performed to check for significant differences in the number of individual samples with signs of collection in different diameter size classes and to test if the proportion of trees harvested is diameter-dependent. 


\section{RESULTS AND DISCUSSION}

\section{Population density and structure}

Two hundred and forty-seven $B$. zanguebarica individuals, in different diameter size classes, were recorded in 1 ha of the study area; this corresponded to a density of 247 individuals/ha. Based on the assessment of diameter size class, the population structure of $B$. zanguebarica showed that individuals are represented in all diameter classes that were arbitrarily selected. The highest number of individuals was observed in DBH $(2-5.9 \mathrm{~cm})$ (Figure 2.A). All individuals in different $\mathrm{DBH}$ were arbitrarily grouped into five tree age stages (seedlings, sapling, juveniles, sub-adults, and adults). Out of the total samples of this plant species, 32 were found in the seedlings category, 21 were grouped as saplings, 120 represented the juvenile categories; sub-adults and adults were 57 and 17, respectively (Figure 2.B). About half (48.6\%) of individuals per hectare were concentrated in the juveniles classes $(2.0-5.9 \mathrm{~cm}$ and $6.0-9.9 \mathrm{~cm})$ followed by the subadults classes $(10.0 \mathrm{~cm} \geq \mathrm{DBH} \leq 25.9 \mathrm{~cm})$ with $23 \%$ of the total tree species. Seedlings contributed to $13 \%$ and saplings represented $8.5 \%$ of the total tree; however, the adult category was under-represented at $6.9 \%$.

Few individuals were recorded for both the lower and the higher stem diameter, whereas a high number of individuals were noted in the medium class. The population structure of $B$. zanguebarica according to the number of individuals per hectare showed a bell-shaped trend (Figure
2.B). The number of individuals increases with increasing of stem diameter up to a certain point, then decreases with increase in stem diameter.

\section{Proportion of plant parts harvested}

A total of two hundred forty-seven individuals of the species B. zanguebarica was recorded in the study area of which hundred $(40.5 \%)$ presented some signs of bark collection, twenty-nine $(11.7 \%)$ showed evidence of roots excavated while nineteen $(7.7 \%)$ had cut stumps which were clearly visible. Overall, one hundred and fifty-three plants $(60 \%)$ out of the total distributed in a different size class and recorded in this study, presented some signs of plant parts extraction. The number of plants showing a different proportion of bark and root extracted is presented in Tables 1 and 2, respectively.

\section{Bark harvested}

Based on the bark collection, the number of plants and the proportion of bark removal varied for different diameter size classes. One hundred forty-seven individuals (59.5\%) out of the 247 found in this population had no evidence of bark extraction, whereas 100 plants $(40.5 \%)$ showed some signs of bark extraction. The extent of bark removal ranged from simple scaling (trace) to the entire removal of the bark from the tree. All size classes presented signs of bark harvested except the lowest diameter class (seedlings $\leq 2$ ).

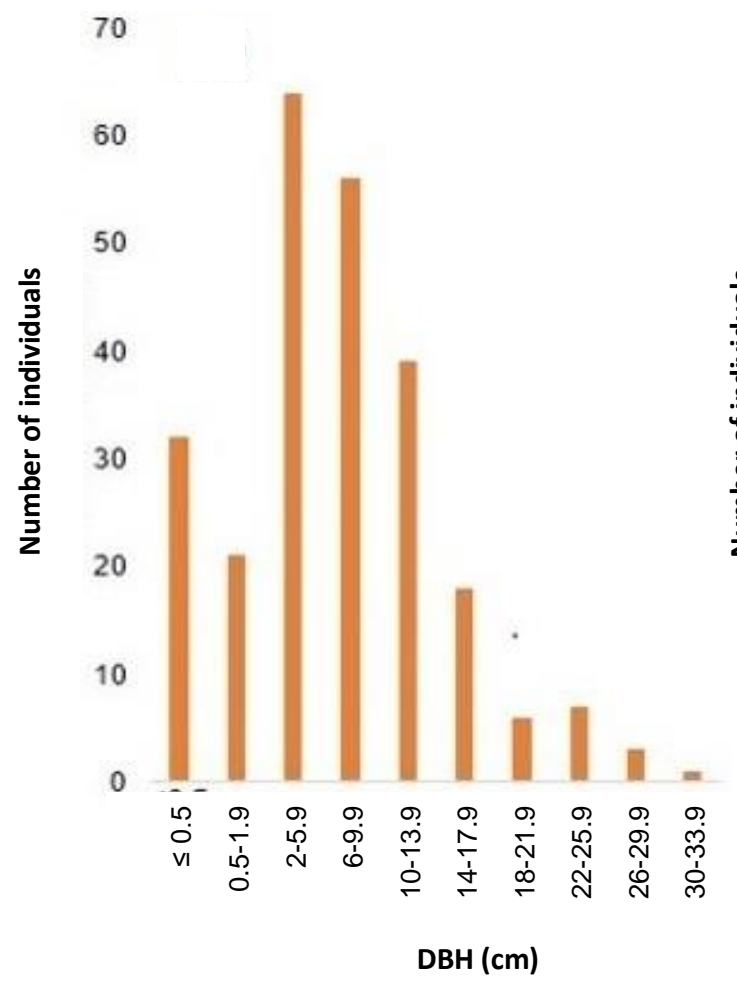

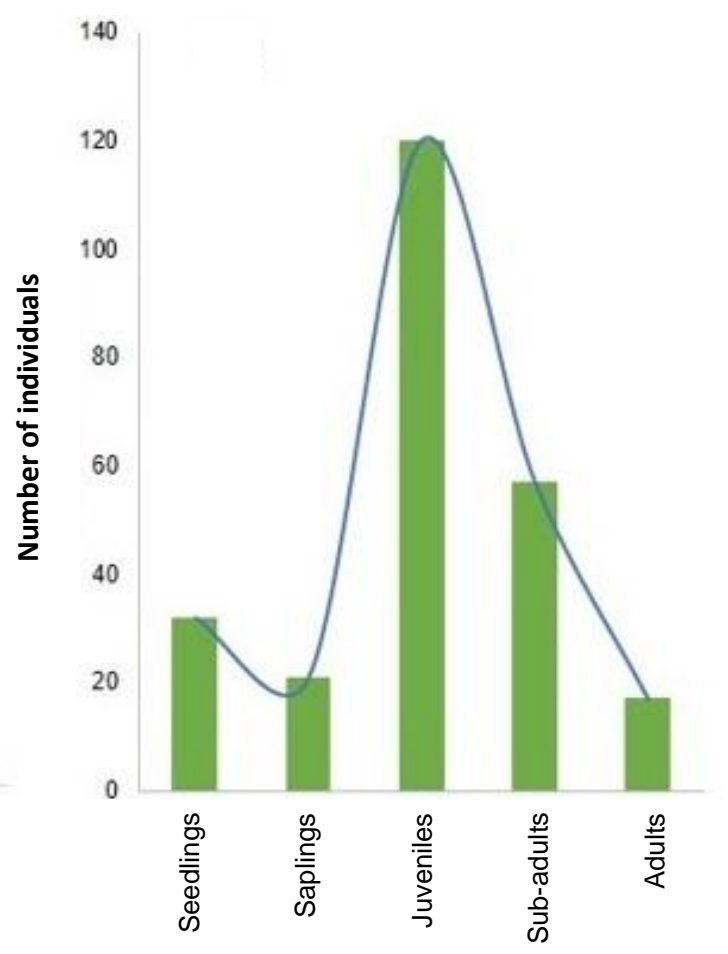

Age stage distribution

Figure 2. Illustration of population of Brackenridgea zanguebarica in the Brackenridgea Nature Reserve. A. Distribution of $B$. zanguebarica in various diameter size classes; B. Patterns of age stage distribution of $B$. zanguebarica 
Table 1. Number of individuals with the sign of bark extraction and proportion of bark harvested in different diameter size classes of Brackenridgea zangueberica

\begin{tabular}{|c|c|c|c|c|c|c|c|c|}
\hline \multirow[b]{2}{*}{ DBH class $(\mathbf{c m})$} & \multirow{2}{*}{$\begin{array}{c}\text { Total } \\
\text { number of } \\
\text { individuals } \\
\text { sampled } \\
\end{array}$} & \multicolumn{6}{|c|}{ Proportion of bark removal } & \multirow{2}{*}{$\begin{array}{c}\text { Total number } \\
\text { of individuals } \\
\text { with bark } \\
\text { harvested } \\
\end{array}$} \\
\hline & & $\begin{array}{c}\text { 0 } \\
\text { (Null) } \\
\text { 0\% }\end{array}$ & $\begin{array}{l}1 \\
\text { (Trace) } \\
1-10 \%\end{array}$ & $\begin{array}{c}2 \\
\text { (Light) } \\
11-25 \%\end{array}$ & $\begin{array}{c}3 \\
\text { (Moderate) } \\
\text { 26-50\% }\end{array}$ & $\begin{array}{l}\quad 4 \\
\text { (Severe) } \\
51-75 \%\end{array}$ & $\begin{array}{c}5 \\
\text { (Very severe) } \\
\text { 76-100\% }\end{array}$ & \\
\hline Seedlings $\leq 0.5$ & 32 & 32 & 0 & 0 & 0 & 0 & 0 & 0 \\
\hline Saplings 0.5-1.9 & 21 & 20 & 0 & 1 & 0 & 0 & 0 & 1 \\
\hline $2-5.9$ & 64 & 53 & 4 & 1 & 3 & 1 & 2 & 11 \\
\hline $6-9.9$ & 56 & 31 & 3 & 7 & 9 & 3 & 3 & 25 \\
\hline $10-13.9$ & 39 & 8 & 4 & 5 & 10 & 7 & 5 & 31 \\
\hline $14-17.9$ & 18 & 3 & 0 & 2 & 4 & 5 & 4 & 15 \\
\hline $18-21.9$ & 6 & 0 & 1 & 0 & 1 & 4 & 0 & 6 \\
\hline $22-25.9$ & 7 & 0 & 1 & 0 & 2 & 3 & 1 & 7 \\
\hline $26-29.9$ & 3 & 0 & 0 & 0 & 1 & 1 & 1 & 3 \\
\hline $30-33.9$ & 1 & 0 & 0 & 0 & 0 & 0 & 1 & 1 \\
\hline Total & 247 & 147 & 13 & 16 & 30 & 24 & 17 & 100 \\
\hline
\end{tabular}

Of those with signs of bark harvested, the highest number (30 plants) was moderately harvested (26-50\%), 24 showed signs of severe bark removal (51-75\%) while, 17 presented very severe signs of bark damaged (76-100\%). Sixteen plants showed evidence of bark lightly exploited $(11-25 \%)$ and the lowest number (13) were found in the trace category $(1-10 \%)$. The greater the DBH of the tree, the more it was harvested and the higher the proportion of bark removal (Table 1). Kruskal-Wallis analyses revealed a significant relationship between the number harvested and the proportion of bark harvested in the diameter size class $(\mathrm{p}<0.05)$.

Concerning the proportion of bark removal for each diameter class, none of the seedlings showed signs of bark removal. The sapling class had 1 plant where $11-25 \%$ of the bark had been collected. In the juvenile category (2-5.9 $\mathrm{cm}$ and $6-9.9 \mathrm{~cm}), 36$ plants $(30 \%)$ out of the 120 in this category showed signs of bark collection with different percentages. Among these 36, 5 had $76-100 \%$ of bark damaged, 4 and 12 plants were found with $51-75 \%$ and 26$50 \%$ of bark extraction, respectively. Eight plants showed $11-25 \%$ and 7 had $1-10 \%$ of their bark extracted. In the sub-adult category $(10-13.9 \mathrm{~cm}$ and $14-17.9 \mathrm{~cm}), 46$ $(80.7 \%)$ out of 57 plants presented bark extraction. Four plants presented traces of bark damaged, and seven were lightly harvested. Fourteen individuals had moderately extracted bark while 12 were found with severe levels of bark removal. Nine plants were recorded in the highest proportion (76-100\%) of bark extracted. In the Adult category $(18-21.9 \mathrm{~cm}$ to $30-33.9 \mathrm{~cm}), 17$ plants $(100 \%)$ showed signs of bark damage (Table 1).

Figure 3 shows the percentage of plants with bark removal in different age stage distribution. In the adult categories, all the plants showed signs of bark extraction from trace to very severe, whereas, in sub-adults' categories, $80.7 \%$ of the plants presented signs of bark removal. $30 \%$ and $4 \%$ of plants were found with signs of bark harvested in the juvenile and seedlings categories. Almost all individuals of the five largest diameter classes that were found within this population, clearly, showed signs of bark removal (Table 1). The majority of the larger stems had been intensely harvested in the past; hence, the larger the stem, the higher the percentage of bark removal (Figure 3). According to the Kruskal-Wallis Test, the number of individuals with the sign of bark harvested is considered insignificant between diameter size classes; $\mathrm{P}$ value of 0.5382 is considered insignificant $(\mathrm{p}<0.05)$.

\section{Root harvested}

Among the total recorded plants (247) in all the diameter size classes, 29 plants (11.7\%) showed some signs of root excavated as opposed to $218(88.3 \%)$, which had no sign of root excavated. Of the 29 plants presenting signs of root damage, $23(79.3 \%)$ had 1-10\% (trace) and 11-25\% (light) of their root extracted. Two plants presented moderate root extraction, 2 others had been severely harvested, while two showed more than $76 \%$ of root collection (Table 2).

Table 2 shows the number of plants with signs of a root collection and the proportion of root harvested in different diameter size classes. The two first classes (seedlings and saplings) showed no sign of root damage. In the juvenile category $(2-5.9 \mathrm{~cm}$ and $6-9.9 \mathrm{~cm}) 4$ samples had $1-10 \%$ of root extracted, 2 indicated light root removal and 2 showed $51-75 \%$ of root damage. Fifteen samples were found with evidence of root extracted in the sub-adult category (10$13.9 \mathrm{~cm}$ to $14-17.9 \mathrm{~cm}$ ); of these, 8 presented trace of root damage, 4 showed slight proportion and 2 plants' roots had been moderately collected. In the adult category, 6 plants showed signs of root damaged of which 2, 3 and 1 had 1$10 \%, 11-25 \%$ and $76-100 \%$ of their roots removed, respectively (Table 2). The number of individuals with signs of root collection, in different diameter size classes, according to Kruskal-Wallis is significantly different ( $\mathrm{p}<$ 0.05 ) between diameter size classes. Figure 4 shows that the larger the DBH class, the higher the percentage of plants with roots excavated. $35.3 \%$ of the samples in the adult categories showed signs of roots collection followed by $26.3 \%$ in sub-adult categories and $6 \%$ in juveniles. 
Table 2. Number of individuals with the sign of root collection and proportion of root harvested in different diameter size classes of Brackenridgea zanguebarica

\begin{tabular}{|c|c|c|c|c|c|c|c|c|}
\hline \multirow[b]{2}{*}{ DBH class $(\mathrm{cm})$} & \multirow[b]{2}{*}{$\begin{array}{l}\text { Total number } \\
\text { of individuals } \\
\text { sampled }\end{array}$} & \multicolumn{6}{|c|}{ Proportion of roots harvested } & \multirow{2}{*}{$\begin{array}{c}\text { Total number } \\
\text { of individuals } \\
\text { with roots } \\
\text { harvested }\end{array}$} \\
\hline & & $\begin{array}{c}\text { 0 } \\
\text { (Null) } \\
\mathbf{0 \%} \\
\end{array}$ & $\begin{array}{c}1 \\
\text { (Trace) } \\
1-10 \%\end{array}$ & $\begin{array}{c}2 \\
\text { (Light) } \\
11-25 \% \\
\end{array}$ & $\begin{array}{c}3 \\
\text { (Moderate) } \\
\mathbf{2 6 - 5 0 \%} \\
\end{array}$ & $\begin{array}{c}4 \\
\text { (Severe) } \\
51-75 \%\end{array}$ & $\begin{array}{c}5 \\
\text { (Very severe) } \\
\mathbf{7 6 - 1 0 0 \%} \\
\end{array}$ & \\
\hline Seedlings $\leq 0.5$ & 32 & 32 & 0 & 0 & 0 & 0 & 0 & 0 \\
\hline Saplings $0.5-1.9$ & 21 & 21 & 0 & 0 & 0 & 0 & 0 & 0 \\
\hline $2-5.9$ & 64 & 61 & 0 & 2 & 0 & 1 & 0 & 3 \\
\hline $6-9.9$ & 56 & 51 & 4 & 0 & 0 & 1 & 0 & 5 \\
\hline $10-13.9$ & 39 & 31 & 4 & 3 & 0 & 0 & 1 & 8 \\
\hline 14-17.9 & 18 & 11 & 4 & 1 & 2 & 0 & 0 & 7 \\
\hline $18-21.9$ & 6 & 4 & 0 & 2 & 0 & 0 & 0 & 2 \\
\hline $22-25.9$ & 7 & 5 & 1 & 1 & 0 & 0 & 0 & 2 \\
\hline $26-29.9$ & 3 & 2 & 1 & 0 & 0 & 0 & 0 & 1 \\
\hline $30-33.9$ & 1 & 0 & 0 & 0 & 0 & 0 & 1 & 1 \\
\hline Total & 247 & 218 & 14 & 9 & 2 & 2 & 2 & 29 \\
\hline
\end{tabular}

\section{Cut stump}

In this study, stem harvested were recorded only in five DBH size classes; from size class $2-5.9 \mathrm{~cm}$ up to size class $18-21.9 \mathrm{~cm}$. In the study area (1 ha), the total number of individuals with their stem cut off was nineteen out of two hundred and forty-seven (7.7\%) of which $8(42.1 \%)$ occurred in the diameter size class $(10-13.9 \mathrm{~cm})$. Four plants were observed with their stems chopped off in each of the diameter size classes 6-9.9 $\mathrm{cm}$ and $14-17.9 \mathrm{~cm}$. In the juvenile category, $5 \%$ of plants presented chopped stems, whereas only $1(5.8 \%)$ was noted with stems cut off in the adult category. Overall, the majority of the samples presenting chopped stems were concentrated in the subadult category $(21 \%)$. In smaller diameter classes (seedlings and saplings) stems chopped off were not observed (Figure 5).

\section{Natural regeneration}

The low number of seedlings (32) and saplings (21) (Figure 2.B) encountered in this study showed low rates of regeneration. Figure 2.B indicated a few individuals from the lower (32 individuals) and higher (16 individuals) stem diameter. Sprouting from few cut stumps (19) was recorded only in the Juvenile, Sub-adult and Adult categories (Figure 5). Only 3 out of $19(15.8 \%)$ cut stumps showed coppice ability (Figure 6).

\section{The main threat to Brackenridgea zanguebarica}

The results of this study revealed that the stem bark was the most collected plant part with about $40.5 \%$ followed by root $(11.7 \%)$ and cut stump $(7.7 \%)$. Overall, $60 \%$ of individuals showed signs of plant part extraction and $40 \%$ of this species showed no damage.

\section{Discussion}

\section{Population density and structure}

The results in terms of DBH size distributions of $B$. zanguebarica population revealed that the majority (48.6 $\%)$ of the plants were in the juvenile categories, although, few plants in both lower and higher diameter size classes were also observed. This result indicated that the low number
(6.9\%) of adult trees is probably due to the destructive harvesting of bark and root. The higher number of individuals in the juvenile stage could be due to the harvesting status of these plants; they are considered not mature enough to be intensely extracted by the harvesters. The higher number of individuals in the juvenile stage could further be due to irregular recruitment episodes when conditions were favorable (Tsheboeng and Murray-Hudson 2013).

The gradual decrease in density from the sub-adult to adult stages is due to past anthropogenic activities that targeted mature plants for bark and root collection, which might have led to reduced reproduction. Similar results have also been reported that populations of species of anthropogenic importance are often characterized by a decrease in occurrences in larger size classes (Botha et al. 2004). Williams et al. (2007) revealed that harvesters tend to select plants in the larger size classes. The structural population pattern of $B$. zanguebarica in this study contradicts that of Tshisikhawe and Van Rooyen (2012) from the same study area, who reported that the population structure of B. zanguebarica exhibited the inverse J-shaped curve, indicating a healthy population structure. This contradiction might be associated with the difference interval of the diameter size classes utilized in each study.

\section{Plant parts harvested}

Bark harvesting. A large number $(40.5 \%)$ of plants showed evidence of bark extraction. In almost all diameter size classes, signs of stem bark collection were noted, which highlights the growing market demand for this multipurpose tree in the area. Despite, the collection of stem bark in almost all the diameter size classes, there was a tendency for more harvesting from trees belonging to the larger diameter classes. This is comprehensible because trees with a large stem diameter have more available bark to harvest than the small ones. These results correspond with other studies, such of Garcinia lucida Vesque (Guedje et al. 2007), Anadenathera colubrina (Soldati et al. 2011) and Myracrodruo nurundeuva (Lins Neto et al. 2008). 


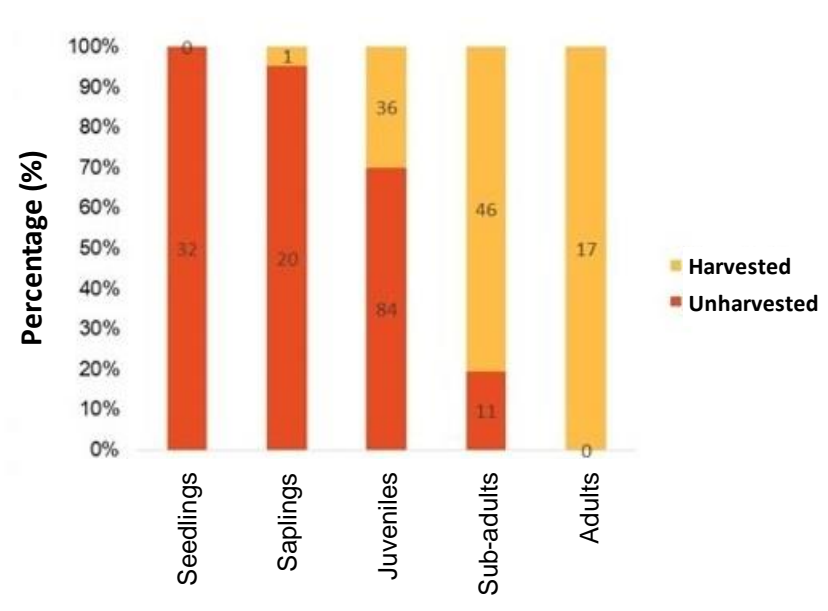

Age stage distribution

Figure 3. Percentage of individuals with bark removal in different age stage

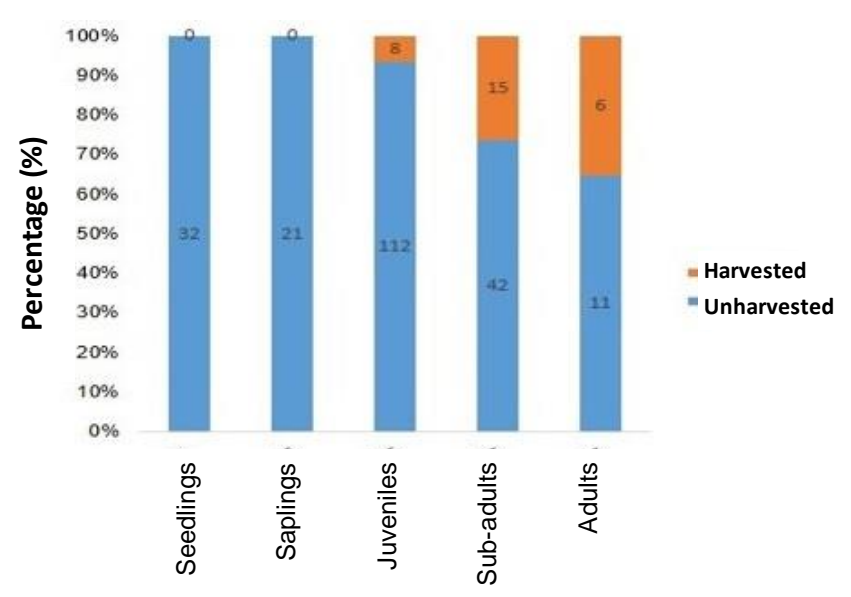

Age stage distribution

Figure 4. Percentage of individuals with root excavated in each age stage

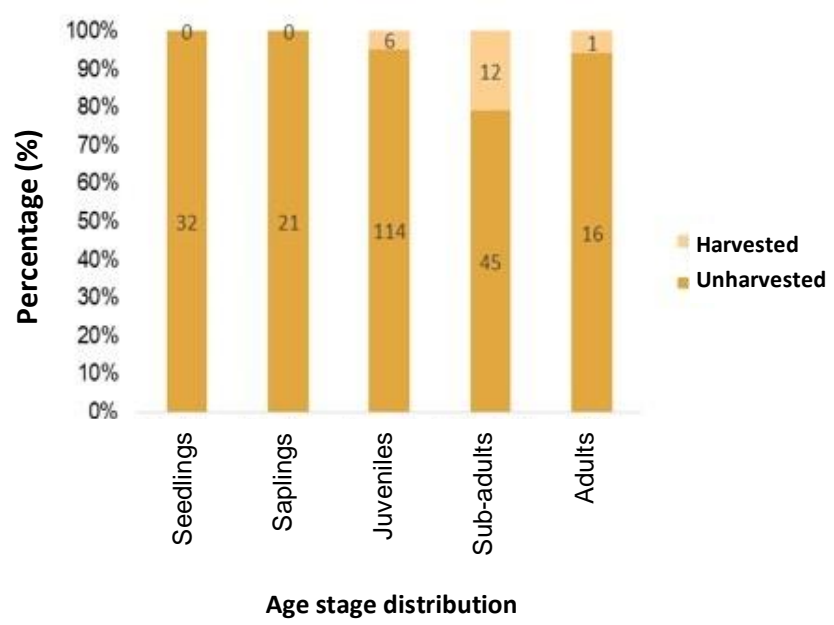

Figure 5. Percentage of individuals with a cut stump in each age stage distribution

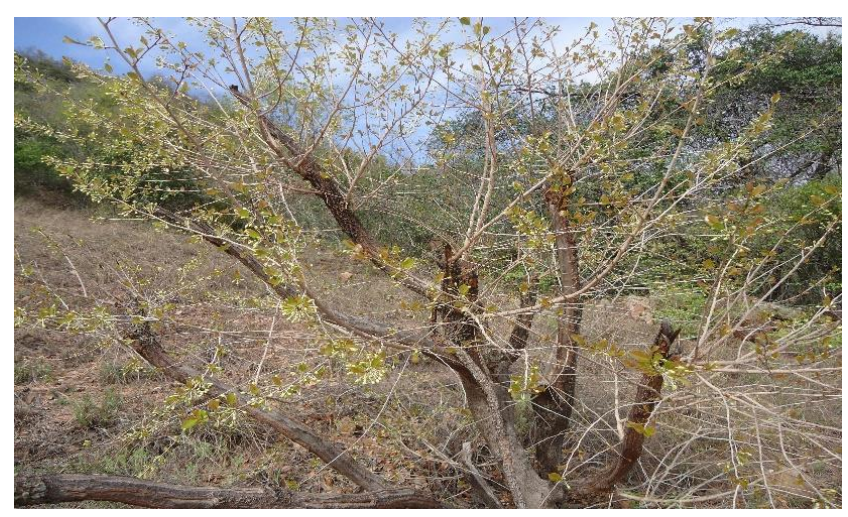

Figure 6. Regeneration from axillary bud (coppice shoot) of $B$. zanguebarica in its natural habitat.

Bark extraction from large plants could affect the survival of reproductive trees as they will not be able to fully recover and will eventually hinder fruit production (Dhillion and Gustad 2004); this will lead to poor seed production. The poor reproduction of this tree species probably increases with the intensity of bark extracted.

The intensive bark collection of B. zanguebarica has caused serious damage to its population because harvesters seem to have no preference about size class. This result supports the findings of the study that revealed the non-size class effect on the extent of bark and foliage harvest of Afzelia africana and Pterocarpus erinaceus in Eastern Burkina Faso (Nacoulma et al. 2011). If the bark is collected from the small-size class trees, it affects the growth and development of this species. Bark harvesting from small plants was reported in some studies such as the study of people's knowledge and extractivism of Stryphnodendron rotundifolium Mart. in Northeastern of Brazil (Feitosa et al. 2014).

The extraction of bark from this multipurpose tree, either from small size classes or from bigger reproductive trees, have had a detrimental impact on the population structure. This species, therefore faces a serious threat from the random collection of bark, which has eventually led to a critically endangered plant. If this trend continues to occur, it is predicted that the population will be extinct in the next years to come.

Root harvesting. In this study, few trees showed evidence of root extraction. A similar situation of root extraction was revealed by Todd (1999), with the number of the tree with root harvested concentrated in the higher diameter classes. Harvesters seem to focus their activities on higher-diameter size classes. The low proportion of root harvested of this tree species may reveal that, this plant part seems not to be the most preferred by harvesters. However, the harvesting impact of root might be responsible for the death of some individuals of this tree species.

\section{Cut stump}

The variation in the number of cut stumps in the different diameter classes reveals the dominance of plants in the intermediate size class. The high number of cut stumps in the medium diameter class may be due to high 
density of medium diameter resulting in a large probability to be found and cut. Few cut stump in this category showed the sprouting ability, which is an important reproduction mechanism to maintain a population viable. Even though many factors influence the ability of a stump to sprout, some studies reveal that one of the most important factors in terms of coppice regeneration is the age of the tree (Johansson and Hjelm 2012).

\section{Natural regeneration}

The majority of individuals found in the medium diameter class of this tree may be due to irregular recruitment and mortality of trees of the larger diameter size classes. The B. zanguebarica status showed a bellshaped pattern with fewer individuals in the seedling, sapling, sub-adult and adult stages compared to the juvenile stage (Figure 2.B). Species with such regeneration pattern is an indication of an unstable population (Helm and Witkowski 2012), and which are under threat due to lower recruitment levels (Colling et al. 2002).

Few numbers of cut stumps observed only in juvenile and sub-adult categories showed the sprouting ability. This may indicate that natural regeneration by coppicing of this species is influenced by the stem diameter size. These findings are also in accord with those of Sangeda and Maleko (2018) who stated that Brachystegia boehmii and B. spiciformis of large size diameter classes did not show much vegetative regeneration. The number of shoots per stump and how long they can start to sprout were not investigated in this study. However, this study showed that $B$. zanguebarica could regenerate vegetatively and this could assist in increasing the regrowth rates of the species.

In conclusion, the overall findings of this study show that the population of $B$. zanguebarica that occurs in the BNR is facing many stresses from human activities which need the reinforcement of certain conservation measures. The harvesting impact on population structure and regeneration showed that $B$. zanguebarica is severely overexploited in the reserve. The destructive harvesting of large individuals influenced the natural regeneration of this plant. The poor natural regeneration is characterized by few seedlings and saplings. Bark harvesting for medicinal and magical purposes is the main threat to the decline of $B$. zanguebarica. The bell-shaped size class distribution pattern characterizes the population structure of $B$. zanguebarica due to the high number of medium-sized trees with a poor number of individuals in both lower and higher DBH size classes. This indicates that the population of $B$. zanguebarica in the reserve is unstable and under threat. The ongoing anthropogenic activities are influencing the population structure and the regeneration status of this tree species. The species has become a critically endangered plant due to the intensive and improper collection of plant parts to supply the growing market demand. This trend may reduce the capacity of this tree species to maintain its population in the coming years. Hence, proper conservation measures have to be formulated to protect the remaining population of $B$. zanguebarica, taking into account not only its multiple values but also for future research. This study is an important step towards the conservation of this threatened plant species. Hence, the following points are made as recommendations: (i) Protection and continuous inventory of the existing populations should be conducted, and it needs the participation of local people. (ii) Conservation through sexual and asexual propagation is urgently needed for overcoming the challenges of natural regeneration. (iii) Regular overnight patrols to reduce illegal harvesting should be implemented by the manager of the reserve. (iv) Ex situ conservation and plantation of $B$. zanguebarica are necessary to expand the new production area in the region.

\section{ACKNOWLEDGEMENTS}

The authors are grateful to the University of Venda, South Africa for providing research funding through the research scheme. We thank the management of Brackenridge Nature Reserve, for allowing us to conduct the study in the reserve. Our gratitude to Maluta for his excellent field assistance.

\section{REFERENCES}

Botha J, Witkowski ETF, Shackleton CM. 2004. Harvesting impacts on commonly used medicinal tree species (Catha edulis and Rapanea melanophloeos) under different land management regimes in the Mpumalanga Lowveld, South Africa. Koedoe 47 (2): 1-18.

Colling G, Matthies D, Reckinger C. 2002. Science Ltd Population structure and establishment of the threatened long-lived perennial Scorzonera humilis in relation to environment. J Appl Ecol 39: 310320 .

Cunningham AB. 1993. African medicinal plants: Setting priorities at the interface between conservation and primary healthcare. People and plants working paper1. UNESCO, Paris.

Dhillion SS, Gustad G. 2004. Local management practices influence the viability of the baobab (Adansonia digitata L.) in different land use types, Cinzana, Mali. Agric Ecosyst Environ 101: 85-103.

Feitosa IS, Albuquerque UP, Monteiro JM. 2014. Knowledge and extractivism of Stryphnodendron rotundifolium Mart. in a local community of the Brazilian Savanna, Northeastern Brazil. J Ethnobiol Ethnomed 10 (64): 1-13.

Guedje NM, Tchamou N, Lejoly J. 2007. Tree response to bark harvest: the case of a medicinal species, Garcinia lucida, as source of raw materials for plant-based drug development. J Appl Biosci 99: 94769491.

Helm CV, Witkowski ETF. 2012. Characterising wide spatial variation in population size structure of a keystone African savanna tree. For Ecol Manag 263: 175-188.

Johansson T, Hjelm B. 2012. The Sprouting Capacity of 8-21-Year-Old Poplars and Some Practical Implications. Forests 3: 528-545.

Lins Neto EMF, Ramos MA, Oliveira RLC, Albuquerque UP. 2008. The Knowledge and harvesting of Myracrondruon urundeuva Allemão by Two Rural Communities in NE Brazil. Funct Ecosyst Commun 2: 66-71.

Michael P. 1990. Ecological Methods for Field and Laboratory Investigations. Tata McGraw-Hill Publishing Company Ltd., New Delhi, India.

Mucina L, Rutherford MC. 2006. The vegetation of South Africa, Lesotho, and Swaziland; Strelitzia 19, South Africa National Biodiversity Institute, Pretoria, South Africa.

Mutshinyalo P. 2011.Brackenridgea zanguebarica Oliv. Walter Sisulu National Botanical Garden. Johannesburg, South Africa.

Mzezewa J, Misi T, van Rensburg LD. 2010. Characterization of rainfall at a semi-arid ecotope in the Limpopo Province (South Africa) and its implications for sustainable crop production. Water SA 36 (1): 19-26. 
Nacoulma BMI, Traoré S, Hahn K, Thiombiano A. 2011. Impact of land use types on population structure and extent of bark and foliage harvest of Afzelia africana and Pterocarpus erinaceus in Eastern Burkina Faso. Intl J Biodivers Conserv 3 (3): 62-72.

Raimondo D, von Staden L, Foden W, Victor JE, Helme NA, Turner RC, Kamundi DA, Manyama PA. 2009. Red List of South African Plants. Strelitzia 25. South African National Biodiversity Institute. Pretoria, South Africa.

Sangeda AZ, Maleko DD. 2018. Regeneration Effectiveness Post Tree Harvesting in Natural Miombo Woodlands, Tanzania. J Plant Sci Agric Res 2 (1):1-10.

Soldati GT, Albuquerque UP. 2010. Impact assessment of the harvest of a medicinal plant (Anadenanthera colubrina (Vell.) Brenan) by a rural semi-arid community (Pernambuco), northeastern Brazil. J Biodivers Sci Ecosyst Serv Manag 6 (3): 106-118.

Todd C. 1999. Mutavhatsindi: A magical medicinal tree from the Soutpansberg. Veld and Flora 85 (1): 17.

Todd CB, Khorommbi K, Van der Waal BC, Weisser PJ. 2004 Conservation of woodland and biodiversity. A complementary traditional and western approach towards protecting Brackenridgea zanguebarica. In: Lawes MJ, Eeley HAC, Shackleton CM, Geach BGS (eds) Indigenous Forests and Woodlands in South Africa Policy, People and Practice. University of KwaZulu-Natal Press. Pietermaritzburg, South Africa.

Tsheboeng G, and Murray-Hudson M. 2013. Spatial variation of population size structure of selected riparian tree species in the Okavango Delta, Botswana. Biodivers Ecol 5: 341-350.
Tshisikhawe MP, Van Rooyen MW. 2012. Population biology of Brackenridgea zanguebarica in the presence of harvesting. J Med Plants Res 6 (46): 5748-5756.

Tshisikhawe MP, Baloyi O, Ligavha-Mbelengwa MH, Bhat RB. 2012. The population ecology of Securidaca longepedunculataFresen. in the Nylsvley Nature Reserve, Limpopo Province, South Africa. Phyton-Int J Exp Bot 81: 107-112.

Tshisikhawe MP, Van Rooyen W, Gaugris JY. 2013. 'Is the present Brackenridgea Nature Reserve large enough to ensure the survival of Brackenridgea zanguebarica Oliv?. Koedoe 55 (1): 1-5.

Van Dyke F. 2003. Conservation biology: Foundations, concepts, applications, McGraw-Hill Companies, New York.

Venter SM, Witkowski ETF. 2010. Baobab (Adansonia digitata L.) density, size-class distribution and population trends between four land-use types in northern Venda, South Africa. For Ecol Manag 259: 294-300.

Vesa CL, Hung ND, Hanoi CT. 2015. System for data processing in FAOVietnam NFA Project, Description of settings and scripts of Open Foris. Project "Support to National Assessment and Long Term Monitoring of the Forest and Tree Resources in Vietnam (NFA)". FAO, Rome.

Williams VL, Witkowskia ETF, Balkwill K. 2007. Relationship between bark thickness and diameter at breast height for six tree species used medicinally in South Africa. S Afr J Bot 73 (3): 449-465.

Williams VL, Raimondo D. 2008. Brackenridgea zanguebarica Oliv. National Assessment: Red List of South African Plants. version 2011.1, viewed 16 April 2012, from http://redlist.sanbi.org/species. 